\title{
Interaction between Liprin- $\alpha$ and GIT1 Is Required for AMPA Receptor Targeting
}

\author{
Jaewon Ko, ${ }^{1}$ Seho Kim, ${ }^{1}$ Juli G. Valtschanoff, ${ }^{2}$ Hyewon Shin, ${ }^{1}$ Jae-Ran Lee, ${ }^{1}$ Morgan Sheng, ${ }^{3}$ Richard T. Premont, ${ }^{4}$ \\ Richard J. Weinberg, ${ }^{2}$ and Eunjoon Kim ${ }^{1}$ \\ ${ }^{1}$ Department of Biological Sciences, Korea Advanced Institute of Science and Technology, Daejeon 305-701, Korea, ${ }^{2}$ Department of Cell Biology and \\ Anatomy, University of North Carolina Neuroscience Center, University of North Carolina at Chapel Hill, Chapel Hill, North Carolina $27599,{ }^{3}$ Center for \\ Learning and Memory, RIKEN-MIT Neuroscience Research Center and Howard Hughes Medical Institute, Massachusetts Institute of Technology, \\ Cambridge, Massachusetts 02139, and ${ }^{4}$ Department of Medicine (Gastroenterology), Duke University Medical Center, Durham, North Carolina 27710
}

Liprin- $\alpha$ is a multidomain protein that interacts with the LAR family of receptor protein tyrosine phosphatases and the GRIP/ABP family of AMPA receptor-interacting proteins. Previous studies have indicated that liprin- $\alpha$ regulates the development of presynaptic active zones and that the association of liprin- $\alpha$ with GRIP is required for postsynaptic targeting of AMPA receptors. However, the underlying molecular mechanisms are not well understood. Here we report that liprin- $\alpha$ directly interacts with GIT1, a multidomain protein with GTPase-activating protein activity for the ADP-ribosylation factor family of small GTPases known to regulate protein trafficking and the actin cytoskeleton. Electron microscopic analysis indicates that GIT1 distributes to the region of postsynaptic density (PSD) as well as presynaptic active zones. GIT1 is enriched in PSD fractions and forms a complex with liprin- $\alpha$, GRIP, and AMPA receptors in brain. Expression of dominant-negative constructs interfering with the GIT1-liprin- $\alpha$ interaction leads to a selective and marked reduction in the dendritic and surface clustering of AMPA receptors in cultured neurons. These results suggest that the GIT1-liprin- $\alpha$ interaction is required for AMPA receptor targeting and that GIT1 may play an important role in the organization of presynaptic and postsynaptic multiprotein complexes.

Key words: postsynaptic density; GIT1; liprin; GRIP; ABP; AMPA receptor

\section{Introduction}

Liprin- $\alpha$ is a multidomain protein that was originally isolated as a binding partner of the LAR receptor protein tyrosine phosphatase (Serra-Pages et al., 1995). Recently, liprin- $\alpha$ was found to associate with the GRIP/ABP family of multi-PDZ proteins (GRIP1 and GRIP2/ABP) (Wyszynski et al., 2002). GRIPs, through their PDZ domains, associate with various proteins including the glutamate receptor (GluR) 2/3 subunits of AMPA glutamate receptors (Dong et al., 1997; Srivastava et al., 1998; Wyszynski et al., 1999), ephrinB ligands, Eph receptor tyrosine kinases (EphB2 and EphA7) (Torres et al., 1998; Bruckner et al., 1999; Lin et al., 1999), and the Ras guanine nucleotide exchange factor (GEF) GRASP-1 (Ye et al., 2000), suggesting that GRIP may function as a scaffold for multiprotein complexes. Intriguingly, interfering with the GRIP-liprin- $\alpha$ interaction by dominant-negative constructs disrupts dendritic and surface expression of AMPA receptors (Wyszynski et al., 2002), suggesting that the GRIP-liprin- $\alpha$ interaction is required for AMPA receptor targeting.

A mutation in syd-2 (synapse-defective 2), a Caenorhabditis elegans homolog of liprin- $\alpha$, leads to lengthening of presynaptic active zones and impaired synaptic transmission (Zhen and Jin, 1999). Mutations in both Dliprin- $\alpha$ and Dlar (Drosophila ho-

\footnotetext{
Received 0ct. 21, 2002; revised Dec. 13, 2002; accepted Dec. 13, 2002.

This work was supported by grants from the Korean Ministry of Science and Technology, the Korea Science and Engineering Foundation, and the Korea Research Foundation.

Correspondence should be addressed to Eunjoon Kim, Department of Biological Sciences, Korea Advanced Institute of Science and Technology, Daejeon 305-701, Korea. E-mail: kime@mail.kaist.ac.kr.

Copyright $\odot 2003$ Society for Neuroscience $\quad 0270-6474 / 03 / 231667-11 \$ 15.00 / 0$
}

mologs of liprin- $\alpha$ and LAR) lead to defects in axon terminal branching and active zone dimensions (Kaufmann et al., 2002). Liprin- $\alpha$ directly associates with RIM, an active zone component that regulates neurotransmitter release (Schoch et al., 2002). These results suggest that, in addition to its involvement in postsynaptic receptor targeting, liprin- $\alpha$ regulates the development of presynaptic active zones. However, little is known about the molecular mechanisms underlying these effects.

GIT is a ubiquitously expressed family of proteins (GIT1/Cat1/p95-APP1 and GIT2/Cat-2/PKL/p95-APP2) known to associate with G-protein-coupled receptor kinases (GRKs) as well as with various focal adhesion proteins including $\beta$ Pix (a Rho-type GEF), focal adhesion kinase (FAK), and paxillin (a multidomain protein) (Premont et al., 1998; Bagrodia et al., 1999; Turner et al., 1999; Di Cesare et al., 2000; Premont et al., 2000; Zhao et al., 2000). GITs contain a GTPase-activating protein (GAP) domain active for ADP-ribosylation factor (ARF), small GTPases that are implicated in the regulation of membrane traffic and actin cytoskeleton (Chavrier and Goud, 1999). Consistently, GIT1 regulates endocytosis of various membrane proteins, including the $\beta 2$-adrenergic receptor (Premont et al., 1998; Claing et al., 2000). GITs also contain several domains for protein interactions, including three ankyrin repeats (ANKs), a spa2 homology domain 1 (SHD), and a C-terminal GRK-binding domain (GRKBD), which mediate their association with $\beta$ Pix, FAK, and paxillin. These results suggest that GIT1 is a multifunctional scaffold that is implicated in the regulation of receptor trafficking, the actin cytoskeleton, and multiprotein assembly. However, the neuronal functions of GIT proteins remain essentially unknown. 
Here we report a direct interaction between liprin- $\alpha$ and GIT1. GIT1 distributes to both presynaptic and postsynaptic sites. GIT1 is enriched in postsynaptic density (PSD) fractions and forms a complex with liprin- $\alpha$, GRIP, and AMPA receptor subunits in brain. Dominant-negative constructs disrupting the GIT1-liprin- $\alpha$ interaction greatly decrease dendritic and surface clustering of AMPA receptors. These results suggest that the GIT1-liprin- $\alpha$ interaction is important for synaptic organization and AMPA receptor targeting.

\section{Materials and Methods}

Yeast two-hybrid. Two-hybrid screen was performed as described (Kim et al., 1995). Bait plasmids for the screen were liprin- $\alpha 4$ (aa 351-1202) and GIT1 (aa 1-770) in pBHA. GIT1 and liprin- $\alpha 1$ deletions were subcloned into pGAD10.

Expression constructs. Dominant-negative constructs containing GRKBD (aa 375-770 of GIT1) and GBD (aa 513-673 of liprin- $\alpha 1$ ) were subcloned into pEGFP-C1 (Clontech, Palo Alto, CA). The following expression constructs have been described: liprin- $\alpha 1$, liprin- $\alpha 1$ A (SerraPages et al., 1995), GRIP2 (Wyszynski et al., 1998), Flag-GIT1 (Premont et al., 1998), and KIF1A (H. Shin and E. Kim, unpublished observations).

Antibodies. H6-GIT1 (aa 1-374 for 1236 antibody; a 375-770 for 1177) and H6-EGFP (aa 1-240, 1173) were used for immunization of guinea pigs. Specific antibodies were affinity-purified using Sulfolink column (Pierce, Rockford, IL) or polyvinylidene difluoride membrane. The following antibodies have been described: GIT1 Du139 (Premont et al., 1998), liprin- $\alpha 1069$ (Wyszynski et al., 2002), GRIP 1756 (Wyszynski et al., 1998), and LAR D5013 (Wyszynski et al., 2002). Other antibodies were purchased: synaptophysin, $\alpha$-actinin, MAP2, vinculin, talin, and Flag (Sigma, St. Louis, MO); ZO-1 and transferrin receptor (Zymed, San Francisco, CA); GluR1 (Oncogene, Boston, MA); GluR2 and GluR 2/3 (Chemicon, Temecula, CA); GAD-6 and HA (Boehringer Manheim, Philadelphia, PA); pTyr 4G10 (Upstate Biotechnology, Lake Placid, NY); and FAK, Pyk2, paxillin, p130Cas, EEA1, and RIM (Transduction Laboratories, Lexington, $\mathrm{KY}$ ).

Immunoprecipitation, immunoblotting, and coclustering assays in heterologous cells. COS cell lysates extracted in $1 \%$ Triton X-100 were immunoprecipitated with Flag $(2.5 \mu \mathrm{g} / \mathrm{ml})$ or $\alpha$-HA $(2.5 \mu \mathrm{g} / \mathrm{ml})$ antibodies and immunoblotted with HA $(1 \mu \mathrm{g} / \mathrm{ml})$ or GIT1 (Du139, 1:2000) antibodies. Coclustering assay was performed as described (Kim et al., 1995).

Fractionation, pull-down, immunoprecipitation, and immunoblotting in rat brain. Pull-down products were analyzed by immunoblotting with liprin- $\alpha$ (1120, $1 \mu \mathrm{g} / \mathrm{ml})$, GRIP $(1 \mu \mathrm{g} / \mathrm{ml})$, GluR2/3 $(1 \mu \mathrm{g} / \mathrm{ml})$, and FAK (1:200) antibodies. In vivo coimmunoprecipitations were performed as described previously (Wyszynski et al., 1999). In brief, deoxycholate (DOC) extracts of the $\mathrm{P} 2$ fraction of adult rat brain were prepared in the presence $(100 \mu \mathrm{g} / \mathrm{ml}$ ) or absence of GST-GIT1 GRKBD (aa 375-770) during detergent extraction and incubated with liprin- $\alpha$ (1120) and GIT1 (1177 or boiled 1177) antibodies. Immunoblotting of the immunoprecipitates and brain fractions was performed using the following antibodies: $\beta$ Pix (1:2000), vinculin (1:1000), Pyk2 (1:1000), LAR $(1 \mu \mathrm{g} /$ $\mathrm{ml})$, RIM $(1 \mu \mathrm{g} / \mathrm{ml})$, p130Cas (1:1000), ZO-1 $(2 \mu \mathrm{g} / \mathrm{ml})$, S-SCAM (1146, $1 \mu \mathrm{g} / \mathrm{ml})$, synaptophysin (1:800), paxillin (1:1000), and talin (1:1000).

Immunoelectron microscopy. Immunoelectron microscopy was performed as described (Wyszynski et al., 1999). GIT1 antibodies (1177) were used at $1 \mu \mathrm{g} / \mathrm{ml}$. For the quantitative study, four sections from each of three rats were labeled with $12 \mathrm{~nm}$ gold particles. Digital images of asymmetric synapses that had clearly outlined synaptic membranes and were labeled with at least one gold particle within $100 \mathrm{~nm}$ of the postsynaptic membrane were randomly acquired $(30,000 \times)$ using a cooled CCD camera (Gatan). Images were analyzed using Scion Image software v.4.0.

Neuron culture, transfection, and immunocytochemistry. Primary hippocampal cultures were prepared from embryonic day (E) 18-19 rat hippocampi. Neurons were transfected at $15 \mathrm{~d}$ in vitro (DIV) using a mammalian transfection kit (Stratagene, La Jolla, CA). The following antibodies were used for colocalization studies: GIT1 $(1177,2 \mu \mathrm{g} / \mathrm{ml})$, liprin- $\alpha$ (1069, $3 \mu \mathrm{g} / \mathrm{ml})$, synaptophysin (1:500), Shank (3856, 1:300), GAD-6 (1:500), EEAl $(3 \mu \mathrm{g} / \mathrm{ml})$, and transferrin receptor $(3 \mu \mathrm{g} / \mathrm{ml})$, followed by Cy3- or FITC-conjugated secondary antibodies (Jackson ImmunoResearch, West Grove, PA). For dominant-negative experiments, neurons 4-6 d after transfection were fixed in cold 100\% methanol or $4 \%$ paraformaldehyde/ $4 \%$ sucrose/PBS, permeabilized in $0.2 \%$ Triton X-100/PBS, and incubated with primary and secondary antibodies in modified GDB buffer (PBS with 3\% horse serum, $0.1 \%$ crystalline grade BSA, and $0.5 \%$ Triton X-100). For surface AMPA receptor staining, transfected neurons were labeled with GluR1 or GluR2 extracellular antibodies $(10 \mu \mathrm{g} / \mathrm{ml})$ for $10 \mathrm{~min}$ at $37^{\circ} \mathrm{C}$, washed with cold DMEM, fixed in $4 \%$ paraformaldehyde $/ 4 \%$ sucrose, and incubated with antiEGFP $(1173,1 \mu \mathrm{g} / \mathrm{ml})$ in modified GDB for $2 \mathrm{hr}$ at room temperature. The following antibodies were used for immunocytochemistry of transfected neurons: EGFP (1173, $1 \mu \mathrm{g} / \mathrm{ml})$, GluR2/3 (2.5 $\mu \mathrm{g} / \mathrm{ml})$, GluR1 (5 $\mu \mathrm{g} / \mathrm{ml})$, GluR2 (5 $\mu \mathrm{g} / \mathrm{ml})$, NMDAR1 (16407, $3 \mu \mathrm{g} / \mathrm{ml})$, Shank (3856, $1: 300)$, and $\alpha$-actinin (1:1000).

Image acquisition and quantification. Fluorescent images were acquired using a confocal microscope (LSM510, Zeiss) and analyzed using MetaMorph image analysis software. The parameter settings were kept constant for all scannings. Transfected neurons were chosen randomly for quantitation from immunostained coverslips from two to five independent experiments. For each neuron studied, one or two largest caliber proximal dendrites were analyzed, and the numbers of puncta were counted and normalized to $100 \mu \mathrm{m}$ length of dendrites after manual tracing and measurement in MetaMorph. Puncta were defined as discrete regions of immunoreactivity at least 10 -fold higher in average intensity than background intensity. Out of focus and nondiscrete regions of staining were excluded from the quantitative analysis. Protrusions with the length of $1-2.5 \mu \mathrm{m}$ were counted as spines. $n$ refers to the number of neurons quantified. Statistical significance was determined by unpaired $t$ test.

\section{Results}

\section{Liprin- $\alpha$ interacts with GIT1 in vitro}

Liprin- $\alpha$-interacting proteins were identified by a yeast twohybrid screen (one million colonies) of a rat brain cDNA library using liprin- $\alpha 4$ (aa 351-1202) as bait. One of the three positive clones was GIT1 (aa 375-770; approximately second half). The others were GRIP1, consistent with the reported liprin- $\alpha$-GRIP interaction (Wyszynski et al., 2002), and the kinesin motor KIF1A (Shin and Kim, unpublished observations). Reverse yeast two-hybrid screen with full-length GIT1 and GIT2 as bait yielded several liprin- $\alpha$-positive clones (data not shown), suggesting that both GIT1 and GIT2 interact with liprin- $\alpha$. Conversely, GIT1 interacted with both liprin- $\alpha 1$ and liprin- $\alpha 4$ (Fig. $1 A$ ). The minimal liprin- $\alpha$-binding region in GIT1 was aa $523-770$ (Fig. $1 A$ ), whereas the minimal GIT1-binding region in liprin- $\alpha$ was aa 513-673 (Fig. 1B).

GIT1 and liprin- $\alpha$ formed a complex in heterologous cells (Fig. 1C,D), indicating that the association occurs in a full-length context in a cellular environment. GIT1, liprin- $\alpha$, and GRIP formed a ternary complex (Fig. 1E), indicating that the GIT1liprin- $\alpha$ and liprin- $\alpha$-GRIP interactions do not interfere with each other. Furthermore, GIT1 and liprin- $\alpha 1$ formed intracellular clusters in heterologous cells when coexpressed, but not if the two proteins were singly expressed (Fig. $1 F$ ). Both GIT1 and GIT2 formed a complex with liprin- $\alpha 1$ and liprin- $\alpha 2$ (data not shown), whereas GIT2 short (a splice variant of GIT2 lacking the liprin- $\alpha$-binding region) did not coimmunoprecipitate with liprin- $\alpha$ (data not shown), confirming the yeast two-hybrid results. Coexpression of $\beta$ Pix markedly increases the GIT1-paxillin interaction in heterologous cells (Zhao et al., 2000), suggesting that $\beta$ Pix unmasks the paxillin-binding region in GIT1. However, coexpression of $\beta$ Pix did not alter the coimmunoprecipitation of GIT1 and liprin- $\alpha$ (data not shown). 
A

GIT1

\begin{tabular}{l|l|l|lll}
1 & 131 & 256 & 375 & & 770 \\
\hline GAP & ANK & SHD & & GRKBD & \\
\hline
\end{tabular}

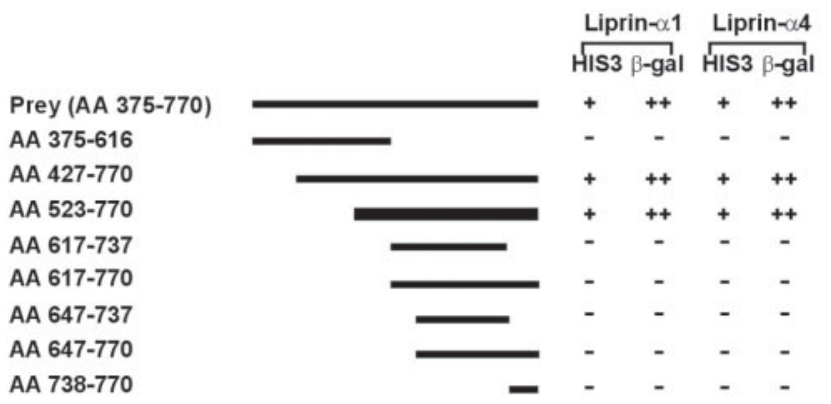

B

Liprin- $\alpha 1$

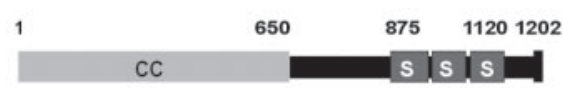

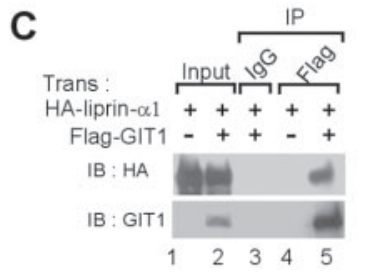

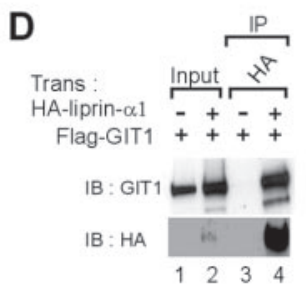

E

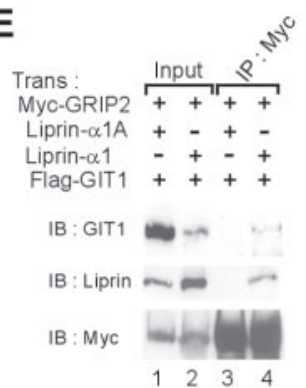

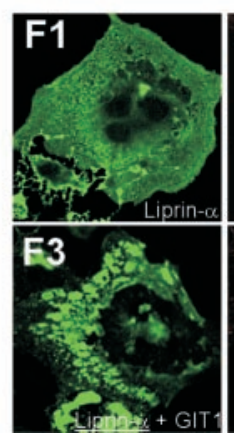

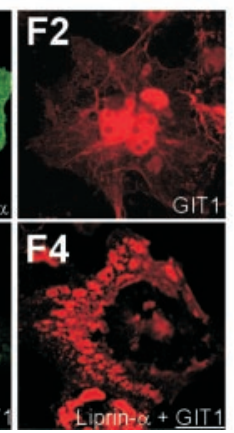

Figure 1. Liprin- $\alpha$ interacts with GIT1 in vitro. A, Minimal liprin- $\alpha$ binding region in GIT1. Deletions of GIT1 were tested for binding to liprin- $\alpha 1$ and liprin- $\alpha 4$ in the yeast two-hybrid assay. The thicker line indicates the minimal region. GAP, GAP domain; ANK, ankyrin repeats; SHD, Spall homology domain; GRKBD, GRK-binding domain. The numbers above the schematic domain indicate boundaries. HIS3 activity: $+++(>60 \%),++(30-60 \%),+(10-30 \%),-($ no significant growth); $\beta$-gal: $+++(<45 \mathrm{~min}),++(45-90 \mathrm{~min}),+(90-240 \mathrm{~min}),-($ no significant $\beta$-gal activity). $B$, Minimal GIT1-binding region in liprin- $\alpha$. CC, Coiled coil domain; S, SAM domain. The PDZ domain-binding motif at the C terminus is indicated by a vertical black line. C, D, Coimmunoprecipitation of GIT1 and liprin- $\alpha$. COS cell lysates doubly or singly transfected with Flag-GIT1 and HA-liprin- $\alpha 1$ were immunoprecipitated with Flag or HA antibodies and immunoblotted with HA and GIT1 (1177) antibodies. Trans, Transfection; IP, immunoprecipitation; IB, immunoblot; Input, 10\% of the extract used for each immunoprecipitation. E, Formation of a ternary complex among GIT1, liprin- $\alpha$, and GRIP. COS cells triply transfected with Flag-GIT1, liprin- $\alpha 1$ (wild-type and liprin- $\alpha 1 \mathrm{~A}$, a splice variant $\alpha 1$ that does not interact with GRIP), and Myc-GRIP2 were immunoprecipitated with Myc antibodies and immunoblotted with the antibodies indicated. Input, 5\%. F, Coclustering between GIT1 and liprin- $\alpha 1$. COS cells singly or doubly transfected with GIT1 and liprin- $\alpha 1$ were labeled by immunofluorescence staining.

Expression pattern and PSD enrichment of GIT1 in rat brain We generated GIT polyclonal antibodies against the C-terminal (1177) and N-terminal (1236) halves of GIT1. The 1177 GIT1 antibody was specific for GIT1, whereas the 1236 antibody reacted equally with GIT1 and GIT2 (Fig. 2A). We used the 1177 and Du139 (Premont et al., 1998) GIT1-specific antibodies for characterization of GIT1 expression in vivo.

GIT1 is widely expressed in rat brain, including cortex, cerebellum, and hippocampus (Fig. 2B). GIT1 expression levels remained constant throughout postnatal development, somewhat similar to those of liprin- $\alpha$ (Fig. 2C) (Wyszynski et al., 2002) and GRIP (Wyszynski et al., 1998). GIT1 and known GIT1-binding proteins (liprin- $\alpha, \beta$ Pix, FAK, and paxillin) are found in actinrich focal adhesions. Because dendritic spines also contain high levels of actin, we hypothesized that these proteins may play a role in the organization of synapses and characterized and compared their subcellular fractionation. In subcellular fractionation analyses, a significant portion of GIT1 was detected in the P2 (crude synaptosome) and P3 (light membranes), but little in the S3 (cytosol), fractions (Fig. 2D). Within the P2 fraction, most of the GIT1 was partitioned into the LP1 (synaptosomal membranes), not the LS2 (synaptic cytosol) or LP2 (synaptic vesicle-enriched fraction). A similar fractionation pattern was observed for liprin- $\alpha, \beta$ Pix, and FAK. In contrast, the FAK-related focal adhe- sion protein Pyk2 was detected mainly in the S3 fraction. Paxillin and vinculin (a paxillin-binding protein) were also associated primarily with the S3 and not P2 or P3 fractions. Notably, a significant fraction of $\beta$ Pix was associated with the LP 2 fraction, suggesting its functional association with synaptic vesicles. These results indicate that various focal adhesion proteins including GIT1 have different subcellular distribution patterns in neurons.

GIT1 was tightly associated with PSD fractions with a significant enrichment in the PSDIII fraction, similar to PSD-95 (Fig. $2 E$ ). Liprin- $\alpha$ and $\beta$ Pix, although similarly enriched in PSD fractions, were slightly less concentrated in the PSDIII fraction (Fig. $2 E$ ). Despite a subcellular distribution similar to GIT1, FAK was not enriched in the PSD. In contrast, Pyk2, although mainly cytosolic (Fig. 2D), was enriched in the PSD, as reported previously (Huang et al., 2001). Paxillin and vinculin were not enriched in the PSD, consistent with their mainly cytosolic distribution (Fig. $2 D)$. Other focal adhesion proteins including p130Cas and talin were not enriched in the PSD. These results indicate that GIT1 and selected focal adhesion proteins (liprin- $\alpha, \beta \mathrm{Pix}$, and Pyk2 but not paxillin) are co-enriched in the PSD.

\section{GIT1 associates with liprin- $\alpha$ in rat brain}

In the pull-down assay on P2 lysates of adult rat brain, GST-GIT1 GRKBD (aa 375-770) brought down liprin- $\alpha$, GRIP, and 


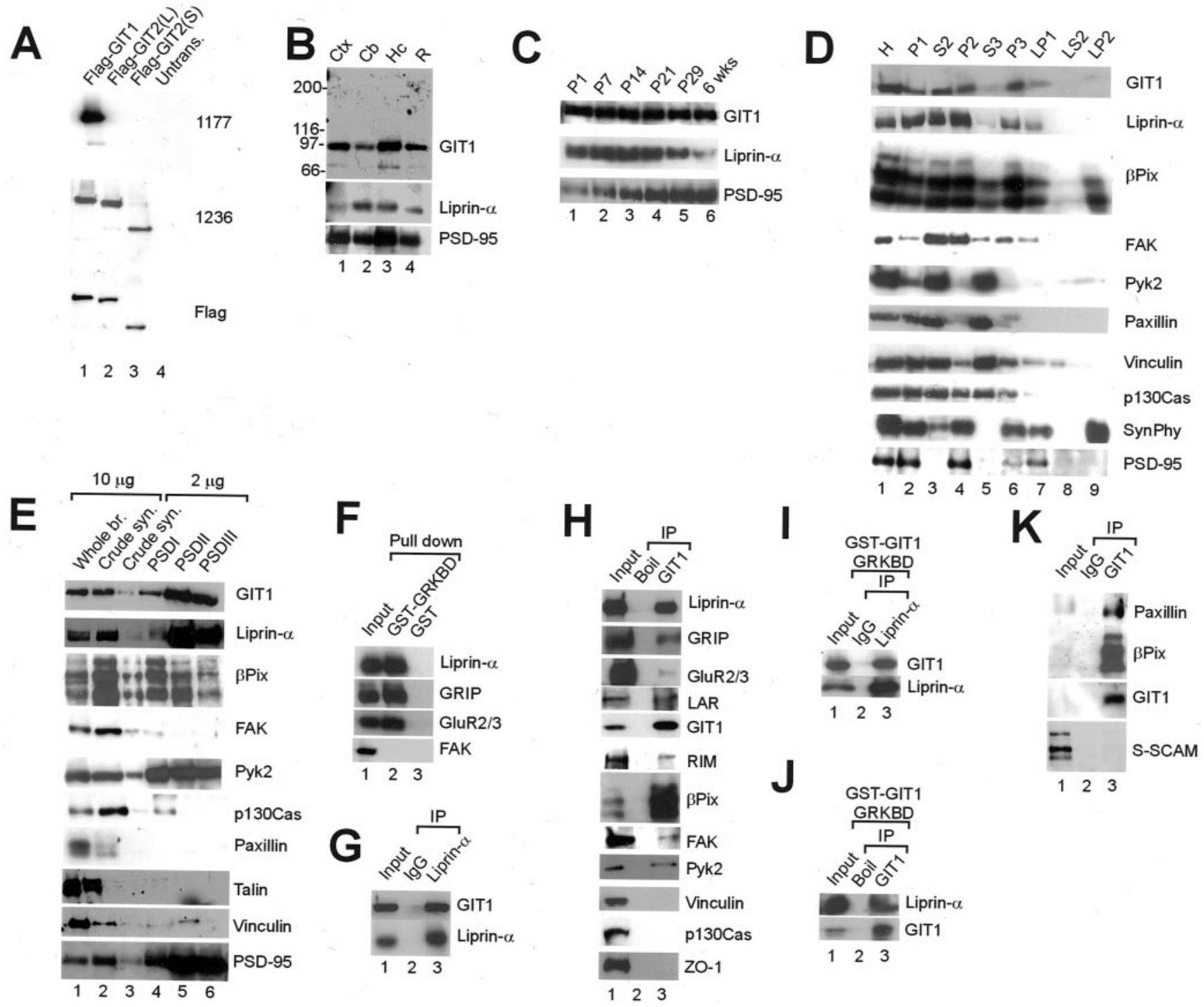

Figure 2. Expression pattern of GIT1 and in vivo association between GIT1 and liprin- $\alpha$. A, Specificity of GIT1 antibodies. COS cells transfected with Flag-GIT1, and GIT2 (L, full-length; S, a shorter splice variant), or untransfected (Untrans.), were immunoblotted with the antibodies indicated. Flag signals were used for normalization. $B$, Regional expression of GIT1. Membranes from various regions of adult rat brain were immunoblotted for GIT1 (Du139), liprin- $\alpha$ (1120), and PSD-95. Ctx, Cortex; Cb, cerebellum; Hc, hippocampus; $R$, the rest of the brain. C, Postnatal expression of GIT1. Membranes from rat brain at the indicated postnatal ages were immunoblotted for GIT1, liprin- $\alpha 1$, and PSD-95. D, Distribution of GIT1 and associated proteins in subcellular fractions of rat brain. SynPhy, Synaptophysin; H, homogenates; $P 2$, crude synaptosomes; $S 2$, supernatant after P2 precipitation; S3, cytosol; P3, light membranes; LP1, synaptosomal membranes; LS2, synaptosomal cytosol; $L P 2$, synaptic vesicle-enriched fraction. E, Enrichment of GIT1 and associated proteins in PSD fractions of rat brain. PSD fractions extracted with Triton X-100 once (PSDI), twice (PSDII), or with Triton X-100 and a strong detergent Sarcosyl (PSDIII) were immunoblotted with the antibodies indicated. Whole br., Whole brain; Crude syn., crude synaptosome. F, Pull-down assay. DOC lysates of the P2 fraction of adult rat brain were incubated with by GST-GIT1 GRKBD, and the pull-down products were immunoblotted for liprin- $\alpha$, GRIP, GluR2/3, and FAK (negative control). Input, $5 \%$. G, $H$, In vivo coimmunoprecipitation between GIT1 and liprin- $\alpha$. P2 fraction lysates were immunoprecipitated with liprin- $\alpha$ (1120) (G) or GIT1 (1177) ( $H$; boiled or untreated) antibodies and immunoblotted with the antibodies indicated. Input, 10\%. I, J, Solubilization and immunoprecipitation were performed as in $G$ and $H$ but in the presence of GST-GIT1 GRKBD. Input, 10\%. $K$, In vivo coimmunoprecipitation of GIT1 and paxillin. The S2 fraction of adult rat brain was immunoprecipitated with GIT1 (1177) antibodies or guinea pig lgG and immunoblotted with GIT1, paxillin, $\beta$ Pix, and S-SCAM (control) antibodies. Input, 10\%.

GluR2/3 (Fig. $2 F$ ), consistent with the association of liprin- $\alpha$ with the AMPA receptor/GRIP complex (Wyszynski et al., 2002). FAK, a protein that binds to SHD but not GRKBD domains of GIT1 (Zhao et al., 2000), was not pulled down, indicating the specificity of the assay.

In coimmunoprecipitation experiments on P2 lysates of rat brain, liprin- $\alpha$ antibodies coprecipitated GIT1 (Fig. 2G). Conversely, GIT1 antibodies brought down liprin- $\alpha$, GRIP and GluR2/3, consistent with the pull-down results, and liprin- $\alpha$ associated LAR and RIM (Fig. $2 H$ ). In addition, GIT1 coimmunoprecipitated with $\beta$ Pix and FAK. Coimmunoprecipitation lev- els of $\beta$ Pix were much higher than those of FAK, consistent with the PSD enrichment of GIT1 and $\beta$ Pix, but not of FAK. Intriguingly, a significant fraction of Pyk2 was coimmunoprecipitated with GIT1. Because GIT1 does not associate with Pyk2 in heterologous cells (data not shown), we presume that their association is indirect. GIT1 did not coimmunoprecipitate with vinculin, p130Cas, or ZO-1, indicating the specificity of the assay. To exclude the possibility that GIT1 and liprin- $\alpha$ artificially associate during detergent extraction, we performed P2 extraction and immunoprecipitation in the presence of GST-GIT1 GRKBD to block the GIT1-liprin- $\alpha$ interaction. GST-GIT1 GRKBD, how- 

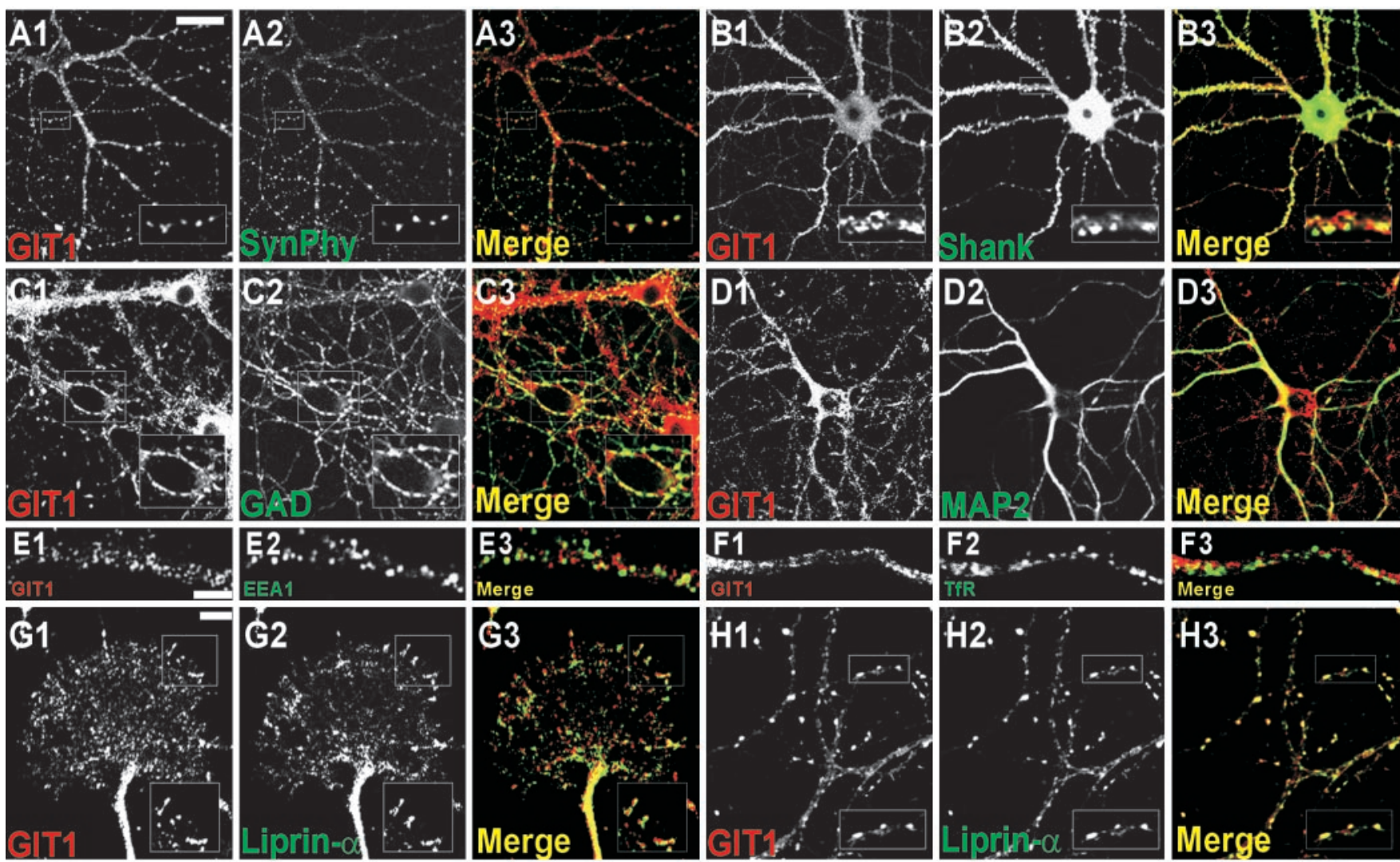

Figure 3. GIT1 colocalizes with liprin- $\alpha$ in cultured neurons. A-H, Double-label immunofluorescence staining of mature hippocampal neurons [21 DIV in medium-density culture except for the I panels (2 DIV)]. Each set of panels (A1/A2/A3, etc.) shows double-label immunostaining for the indicated proteins and merged images. Boxed regions in each set of panels were magnified for better visualization of colocalization. The $G$ panels show a growth cone in immature neurons. Scale bars: $A-D, 30 \mu \mathrm{m} ; E, F, 5 \mu \mathrm{m} ; G, H, 10 \mu \mathrm{m}$.

ever, did not affect the coimmunoprecipitation of GIT1 and liprin- $\alpha$ in either direction (Fig. 2I,J).

Although paxillin was barely detectable in the P2 fraction, because significant amounts of both paxillin and GIT1 are present in the $\mathrm{S} 2$ fraction (Fig. $2 D$ ), we tested whether they form a complex in the S2 fraction. Coimmunoprecipitation experiments showed that GIT1 complexed with paxillin and $\beta$ Pix, but not with S-SCAM (an unrelated PDZ protein) (Fig. $2 \mathrm{~K}$ ), indicating that different subcellular fractions contain GIT1 complexes of differing composition.

\section{GIT1 colocalizes with liprin- $\alpha$ in cultured neurons}

We determined the subcellular localization of GIT1 and its colocalization with liprin- $\alpha$ in cultured hippocampal neurons (Fig. 3). GIT1-immunoreactive structures (as revealed by the 1177 GIT1-specific antibody) were widely distributed in a punctate pattern in various subcellular regions, including synaptic sites (see below). GIT1 staining was eliminated by preincubation of the antibody with immunogen (data not shown). Punctate staining by the 1177 GIT1 antibody extensively overlapped with staining by the 1236 GIT antibody (reacts equally with GIT1 and GIT2) (data not shown), suggesting the authenticity of the GIT1 staining. Some GIT1 puncta colocalized with synaptophysin, a synaptic marker (Fig. 3A). GIT1 colocalized with Shank and GAD, suggesting that GIT1 distributes to both excitatory and inhibitory synaptic sites (Fig. $3 B, C$ ). GIT1 was detected in both MAP2-positive dendrites and MAP2-negative axons (Fig. 3D) and in neurofilament- $\mathrm{H}$ - or tau-positive axons (data not shown). This pattern of GIT1 distribution (dendritic/axonal and excita- tory/inhibitory) resembles that of liprin- $\alpha$ and GRIP (Srivastava et al., 1998; Dong et al., 1999; Wyszynski et al., 1999, 2002).

Because a fraction of GIT1 is detected in nonsynaptic light membrane (P3) fraction (Fig. 2D) and we can observe some nonsynaptic GIT1 puncta in cultured neurons (data not shown), we examined whether GIT1 staining colocalized with endosomal markers. Overall, GIT1 showed little colocalization with EEA1 (early endosome antigen 1; early endosomal marker) (Fig. $3 E$ ) and TfR (transferrin receptor; recycling endosomal marker) (Fig. $3 F$ ), although there were some sites of punctate colocalizations. These results suggest that the GIT1 puncta that do not overlap with endosomal markers in neurites may represent novel supramolecular complexes, making them similar in distribution to the GIT1-containing cytoplasmic complexes that minimally overlap with endosomal and Golgi complexes observed in nonneuronal cells (Manabe Ri et al., 2002).

We next directly compared the subcellular distribution of GIT1 and liprin- $\alpha$ in cultured neurons. In immature neurons (2 DIV), GIT1 colocalized with liprin- $\alpha$ at the tips of growth cones (Fig. $3 G$ ), sites where liprin- $\alpha$ and GRIP colocalize (Wyszynski et al., 2002). In mature neurons (21 DIV), GIT1 and liprin- $\alpha$ showed extensive punctate colocalization along the neurites (Fig. $3 H$ ). These results indicate that GIT1 colocalizes with liprin- $\alpha$ in neurons at various stages of development.

\section{Ultrastructural localization of GIT1 in rat brain}

Postembedding immunogold electron microscopy (EM) of GIT1 was performed on tissue from brains of adult rats, using the 1177 GIT1-specific antibody (Fig. 4). In layers II and III of the somato- 


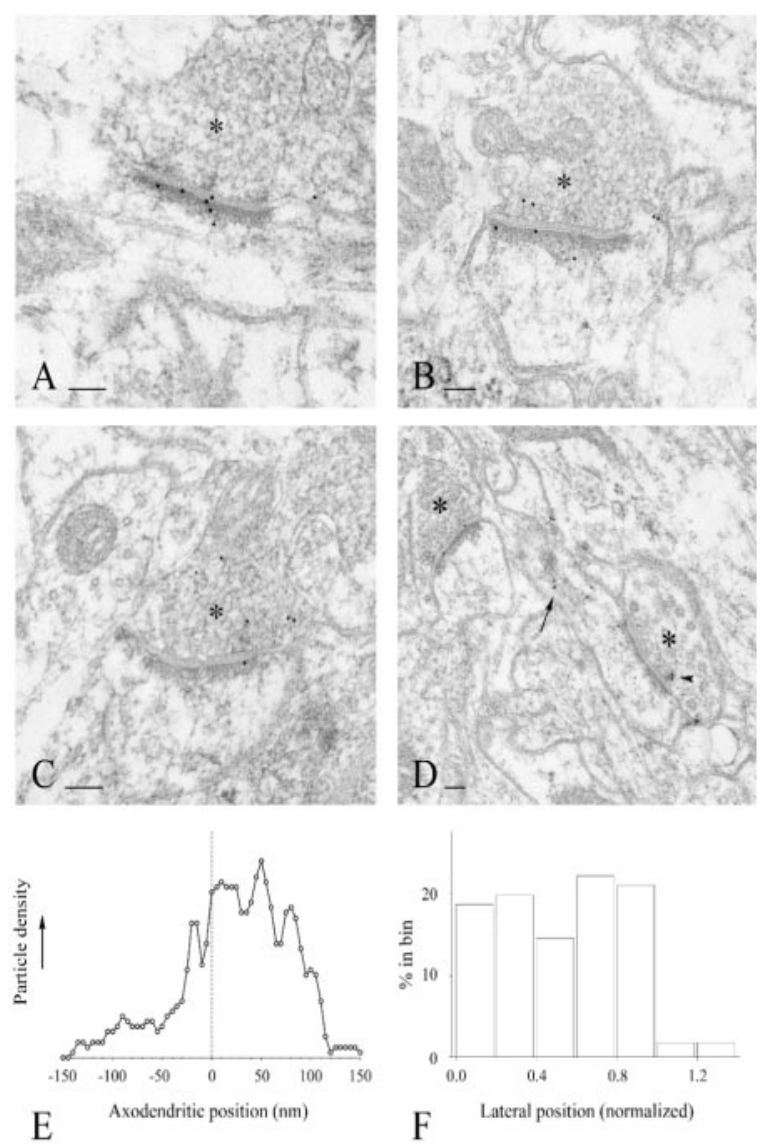

Figure 4. Immunogold-EM localization of GIT1 in rat somatic sensory cortex. $A-D$, GIT1 labeling was associated primarily with asymmetric synapses, involving dendrites $(A)$ and dendritic spines $(B-D)$. Synaptic labeling was mainly over the postsynaptic density. In some synapses, the presynaptic terminal (asterisks) was also labeled. In some cases, gold particles were seen over the spine apparatus ( $D$, arrow) and presynaptic dense projections ( $D$, arrowhead). Scale bars, $100 \mathrm{~nm}$. E, F, Quantitative analysis of the distribution of GIT1 immunogold particles at synapses. E, Distribution along the axo-dendritic axis. Abscissa represents distance from the center of each gold particle to the outer leaflet of the postsynaptic membrane $(0 \mathrm{~nm}$, dashed line); ordinate is labeling density in arbitrary units. Data ( $5 \mathrm{~nm}$ bins) were smoothed using a five-point weighted running average. $F$, Lateral distribution of gold particles along the synapse (only those within $150 \mathrm{~nm}$ of the postsynaptic membrane were considered). Lateral position is normalized; the center of the active zone corresponds to 0 ; the edge corresponds to 1.0 .

sensory cortex, most of the GIT1 gold particles were associated with synapses. Synaptic labeling was predominantly over the PSD of asymmetric synapses, although immunoreactivity was also detected over the presynaptic nerve terminal (Fig. $4 B-D$ ). In six random grid squares from one rat, 211 of 300 asymmetric synapses $(70 \%)$ were labeled with at least one gold particle within $100 \mathrm{~nm}$ of the postsynaptic membrane; a markedly lower fraction (only 5 of 63) of symmetric synapses were labeled. In material embedded in Lowicryl, the labeling was stronger, with more particles remote from the PSD, but an association with the synapse was unequivocal for tissue embedded in both plastics. Labeling was occasionally detected over the spine apparatus, and in some cases gold particles lay over presynaptic dense projections (Fig. $4 D$ ), consistent with our recent finding that GIT1 interacts directly with Piccolo, a presynaptic active zone protein (Kim et al., 2003). Relatively little labeling was found in dendrites and somata.

When the distribution of GIT1 immunogold particles was quantified, particle density along the axo-dendritic axis was maximal over the PSD and the subsynaptic web $(0-60 \mathrm{~nm}$ from the postsynaptic membrane), gradually diminishing into the postsynaptic profile (Fig. $4 E$ ). A secondary peak at $-20 \mathrm{~nm}$ corresponded to labeling of the presynaptic membrane and synaptic vesicles in the immediate vicinity of the synapse, consistent with the GIT1-Piccolo interaction. The lateral distribution of particle density was rather uniform along the PSD (Fig. $4 F$ ), declining markedly outside the active zone. Taken together, the immuno-EM data indicate that GIT1 is enriched on both sides of the synapse in rat brain, which is similar to the ultrastructural localization of liprin- $\alpha$ (Wyszynski et al., 2002) and GRIP (Srivastava et al., 1998; Dong et al., 1999; Wyszynski et al., 1999).

\section{Dominant-negative constructs interfering with the GIT1- liprin $\alpha$ interaction disrupt dendritic and surface clustering of AMPA receptors}

The liprin- $\alpha$-GRIP interaction is important for synaptic targeting and surface expression of AMPA receptors (Wyszynski et al., 2002). Because GIT1 interacts directly with liprin- $\alpha$, we wondered whether this interaction might be important for AMPA receptor targeting. To test this hypothesis, we used two complementary dominant-negative constructs designed to disrupt the GIT1-liprin- $\alpha$ interaction: EGFP-tagged GIT1 GRKBD (containing the minimal liprin- $\alpha$ binding region in GIT1, termed EGFP-GRKBD) and EGFP-liprin- $\alpha$ GBD (minimal GIT1binding region in liprin- $\alpha 1$; EGFP-GBD).

In cultured hippocampal neurons transfected with EGFPGRKBD, there was a dramatic reduction in the number of dendritic clusters of endogenous AMPA receptors (density of GluR2/3 puncta $=2.3 \pm 0.9 / 100 \mu \mathrm{m}$ of dendrite length; mean \pm SD; $n=30$ cells) (Fig. $5 A, I)$ compared with untransfected cells $(32.0 \pm 5.8 / 100 \mu \mathrm{m} ; n=15)$ (Fig. $5 I$ ) or cells transfected with EGFP alone (30.2 $\pm 3.5 / 100 \mu \mathrm{m}$ dendrite; $n=15)$ (Fig. $5 B, I)$. In contrast, EGFP-GRKBD expression had no significant effect on the number of dendritic clusters of endogenous Shank [37.3 \pm $9.5 / 100 \mu \mathrm{m}(n=20)$ vs $42.1 \pm 12.7 / 100 \mu \mathrm{m}$ in untransfected cells] (Fig. 5C,I), NMDAR1 [41.5 $\pm 14.6 / 100 \mu \mathrm{m}(n=12) \mathrm{vs}$ $50.4 \pm 12.3 / 100 \mu \mathrm{m}$ in untransfected cells; Fig. $5 D, I), \alpha$-actinin $(43.2 \pm 12.4 / 100 \mu \mathrm{m}[n=20]$ versus $48.3 \pm 11.4 / 100 \mu \mathrm{m}$ in untransfected cells] (Fig. $5 E, I$ ), or the number of dendritic spines $[32.1 \pm 7.7 / 100 \mu \mathrm{m}(n=14)$ vs $34.1 \pm 2.6 / 100 \mu \mathrm{m}$ in cells transfected with EGFP alone; data not shown]. These results indicate that overexpression of EGFP-GRKBD selectively disrupts dendritic clustering of AMPA receptors.

Surface expression of AMPA receptors was also measured by labeling living neurons with antibodies directed against the extracellular regions of GluR1 or GluR2. Overexpression of EGFPGRKBD in cultured hippocampal neurons dramatically reduced surface expression of endogenous GluR1 and GluR2 on dendritic segments [GluR1 puncta $=22.0 \pm 7.5 / 100 \mu \mathrm{m}$ of dendrite length $(n=16)$; GluR2 $=6.6 \pm 4.3 / 100 \mu \mathrm{m}(n=14)]$ (Fig. $5 F, G)$ compared with untransfected cells [GluR1 $=83.9 \pm 15.8 / 100$ $\mu \mathrm{m}(n=16)$; GluR2 $=57.1 \pm 13.9 / 100 \mu \mathrm{m}(n=14)]$, or cells transfected with EGFP alone $[$ GluR2 $=54.2 \pm 10.4 / 100 \mu \mathrm{m}(n=$ 10)] (Fig. 5H; quantified in Fig. $6 E$ ). The dominant-negative effects on both GluR1 and GluR2, despite the known interaction of GRIP with GluR2/3 but not GluR1, may be caused by their heteromeric multimerization in hippocampal neurons (Wenthold et al., 1996). Taken together, these results suggest that the GIT1liprin- $\alpha$ interaction is important for surface expression of AMPA receptors.

To demonstrate that our dominant-negative constructs indeed disrupt the GIT1-liprin- $\alpha$ interaction, we performed competitive coimmunoprecipitation experiments in heterologous 

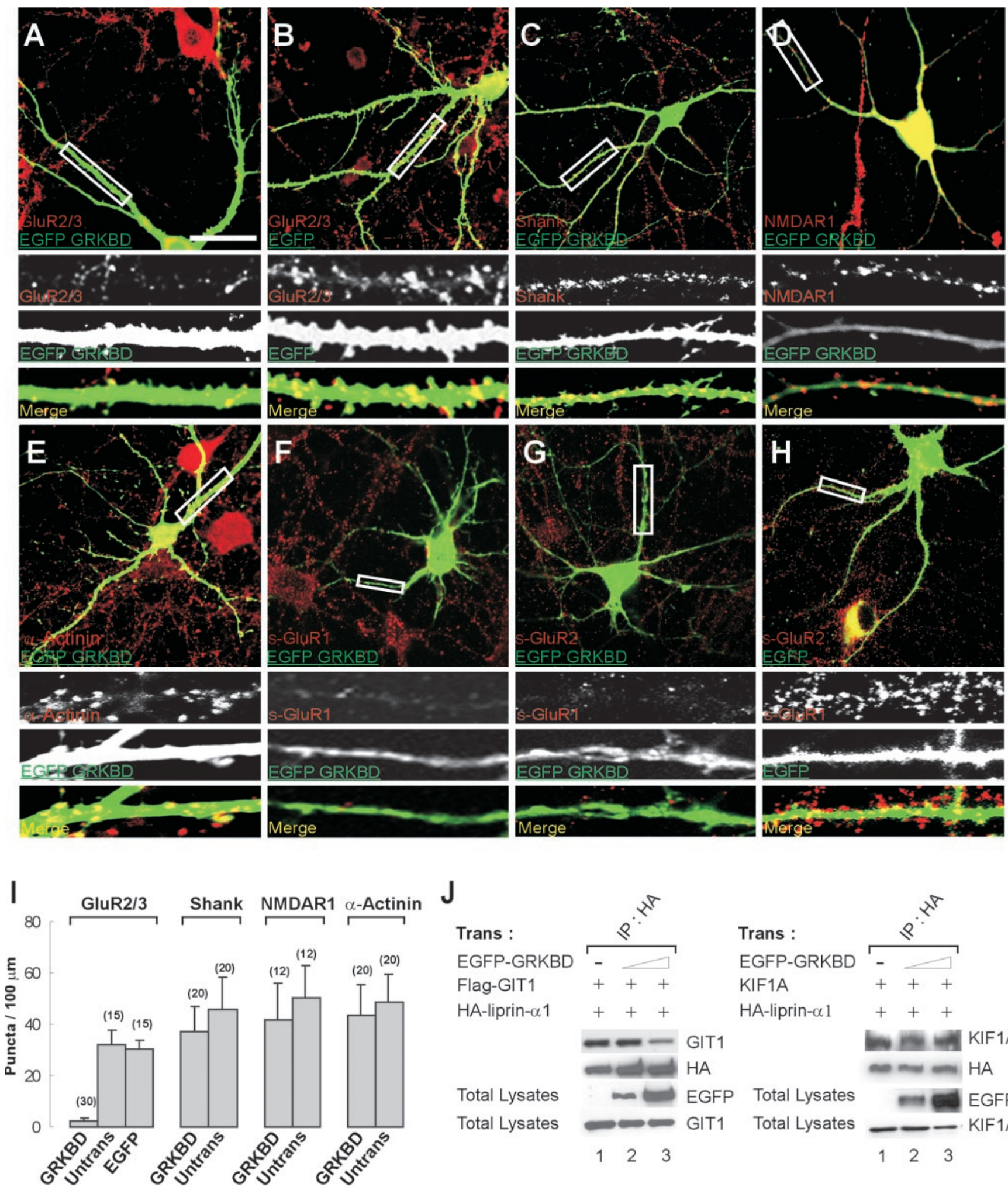

Trans :
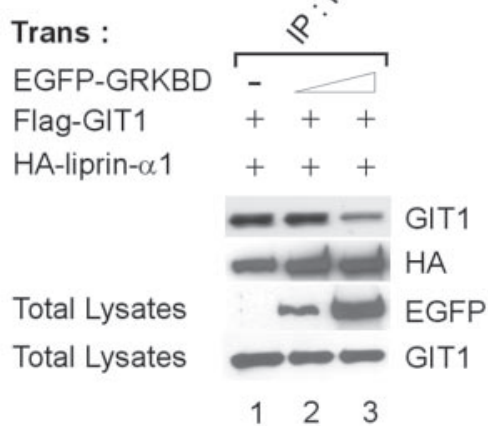
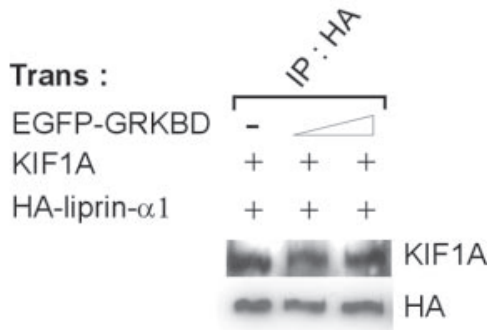

Total Lysates

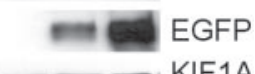

Total Lysates

123

Figure 5. Overexpression of EGFP-GRKBD disrupts dendritic clustering and surface expression of AMPA receptors. $A-H$, Cultured hippocampal neurons were transfected at 15 DIV with either EGFP-GRKBD $(A, C, D-G)$ or EGFP alone $(B, H)$ and doubly labeled at $19-20$ DIV for EGFP-GRKBD or EGFP ( green) and endogenous proteins (red), including GluR2/3 $(A, B)$, Shank (C), NMDAR1 (D), $\alpha$-actinin (E), surface GluR1 (F, s-GluR1), and surface GluR2 (G,H,s-GluR2). Transfected neurons were detected using EGFP antibodies. Boxed regions are shown at higher magnification below each panel in gray scale for individual channels and in color for merged images. Scale bars, $40 \mu \mathrm{m}$. I, Quantitation of the density of dendritic puncta of endogenous GluR2/3, Shank, NMDAR1, and $\alpha$-actinin. Histograms (mean \pm SD) show the density of puncta per $100 \mu \mathrm{m}$ of dendrite length. Numbers $(n)$ are indicated in the parentheses. $J$, HEK293T cells triply transfected with Flag-GIT1 or KIF1A, HA-liprin- $\alpha 1$, and increasing amounts of EGFP-GRKBD were immunoprecipitated with HA antibodies and immunoblotted with the antibodies indicated. 

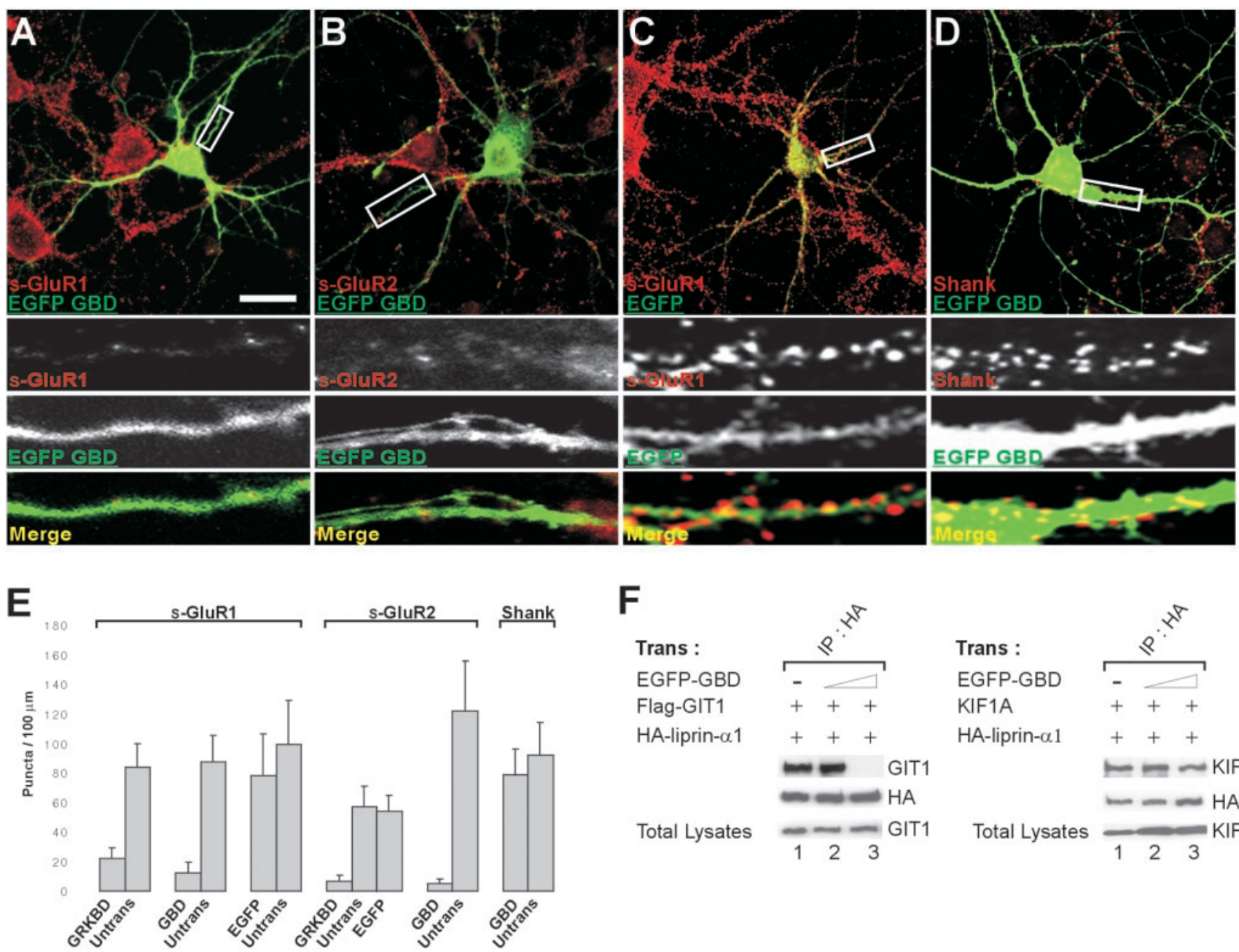

$\mathbf{F}$

Trans :

EGFP-GBD

Flag-GIT1

HA-liprin- $\alpha 1$

Total Lysates

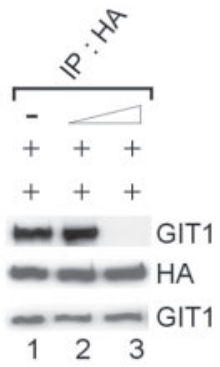

Trans : EGFP-GBD KIF1A HA-liprin- $\alpha 1$

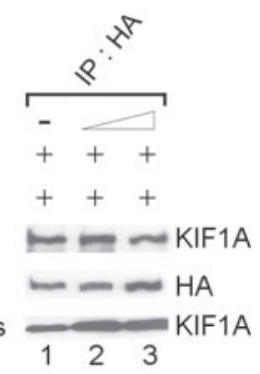

Figure 6. Overexpression of EGFP-GBD disrupts surface expression of AMPA receptors. $A-D$, Cultured hippocampal neurons were transfected at 15 DIV either with EGFP-GBD $(A, B, D)$ or with EGFP alone ( $C$ ) and doubly labeled at 19-20 DIV for EGFP-GBD or EGFP ( green) and endogenous s-GluR1, s-GluR2, or Shank (red). Scale bars, $25 \mu \mathrm{m}$. E, Quantitation of the density of dendritic puncta of endogenous s-GluR1, s-GluR2, and Shank. F, HEK293T cells triply transfected with Flag-GIT1 or KIF1A, HA-liprin- $\alpha 1$, and increasing amounts of EGFP-GBD were immunoprecipitated with HA antibodies and immunoblotted with the antibodies indicated.

cells. These experiments also addressed the possibility that our dominant-negative constructs might disrupt the liprin- $\alpha-\mathrm{KIF} 1 \mathrm{~A}$ interaction, because the GIT1-binding region in liprin- $\alpha$ (aa 513-673) is contained within the KIF1A-binding region in liprin- $\alpha$ (aa 351-673) (Fig. 1B). In human embryonic kidney (HEK) 293T cells triply transfected with GIT1, liprin- $\alpha$, and EGFP-GRKBD, coimmunoprecipitation between GIT1 and liprin- $\alpha$ was reduced significantly by increasing expression of EGFP-GRKBD (Fig. 5J), whereas that between KIF1A and liprin- $\alpha$ was not affected (Fig. $5 J$ ). Similarly, EGFP-GBD selectively eliminated the association of liprin- $\alpha$ with GIT1, but not with KIF1A (Fig. 6F).

In dominant-negative experiments in a reverse orientation, neurons transfected with EGFP-GBD showed a marked reduction in surface expression of endogenous GluR1 and GluR2 [density of GluR1 surface puncta $=12.2 \pm 7.5 / 100 \mu \mathrm{m}(n=16)$ vs $87.5 \pm 17.7 / 100 \mu \mathrm{m}$ in untransfected cells; GluR2 $=5.3 \pm 3.0 /$ $100 \mu \mathrm{m}(n=18) \mathrm{vs} 121.7 \pm 34.3 / 100 \mu \mathrm{m}$ in untransfected cells] (Fig. $6 A, B, E$ ). In contrast, EGFP alone had no significant effect on surface expression of GluR1 [78.4 $\pm 28.1 / 100 \mu \mathrm{m}(n=10)$ vs $99.2 \pm 29.8 / 100 \mu \mathrm{m}$ in untransfected cells] (Fig. $6 C, E$ ). In addition, EGFP-GBD did not significantly change dendritic clustering of endogenous Shank $[78.9 \pm 17.5 / 100 \mu \mathrm{m}(n=10)$ vs $92.1 \pm$
22.2/100 $\mu \mathrm{m}$ in untransfected cells] (Fig. 6D,E), or the number of dendritic spines $[28.9 \pm 8.4 / 100 \mu \mathrm{m}(n=14)$ vs $34.1 \pm 2.6 / 100$ $\mu \mathrm{m}$ in cells transfected with EGFP alone; data not shown]. Taken together, these results point to a key role for the GIT1-liprin- $\alpha$ interaction in dendritic and surface clustering of AMPA receptors.

\section{Discussion}

Focal adhesion proteins at postsynaptic sites

Focal adhesions not only provide a link between the extracellular matrix and the actin cytoskeleton, they are also sites for the integration of a diverse range of signals from cell surface receptors (Turner, 2000). Our results indicate that some of the key organizers of focal adhesions (GIT1, liprin- $\alpha, \beta$ Pix, and Pyk2, but not FAK, paxillin, or p130Cas) are enriched in PSD fractions and form coimmunoprecipitable complexes (Fig. 2 E, H). These PSDenriched multidomain focal adhesion proteins are likely to be involved in the organization of the PSD. In support of this, our results suggest that GIT1 regulates AMPA receptor targeting through its interaction with liprin- $\alpha$ (see below for further discussion). DPix, a Drosophila homolog of mammalian Pix, plays a major role in regulating postsynaptic structure and protein targeting (Parnas et al., 2001). Pyk2 is implicated in synaptic recruit- 
ment of the Src family tyrosine kinases (Girault et al., 1999). It is notable that paxillin, a key organizer of focal adhesions, is not enriched in the PSD (Fig. $2 E$ ) and is present mostly in the extrasynaptic cytosolic fraction (Fig. $2 D$ ), although it still forms a complex with GIT1 and $\beta$ Pix within this fraction (Fig. $2 \mathrm{~K}$ ). These results suggest that paxillin may contribute minimally to the organization of the PSD and instead may have a unique role in extrasynaptic complexes containing paxillin, GIT1, and $\beta$ Pix. This is reminiscent of the recent report that in fibroblast GIT1 cycles between distinct subcellular compartments, including adhesion-like structures, leading edges, and a novel cytoplasmic complex (Manabe Ri et al., 2002).

\section{The GIT1-liprin- $\alpha$ interaction and active zones}

Genetic studies in C. elegans, Drosophila, and mouse have indicated that liprin- $\alpha /$ SYD- 2 regulates the structure and function of presynaptic active zones (Zhen and Jin, 1999; Kaufmann et al., 2002; Schoch et al., 2002). Here we demonstrate that liprin- $\alpha$ associates with GIT1 in vitro and in vivo (Figs. 1, 2). Our EM data indicate that a significant fraction of GIT1 is presynaptic, forming a sharp peak around the active zone (Fig. 4). Moreover, we recently identified a direct association of GIT1 with Piccolo/aczonin (Kim et al., 2003), a multidomain scaffolding protein ( $\sim 530$ $\mathrm{kDa}$ ) enriched in the active zone (Wang et al., 1999; Fenster et al., 2000). Considering our observation that GIT1, a multimodular protein, is implicated in the regulation of receptor targeting and protein assembly at postsynaptic sites, the Piccolo-GIT1liprin- $\alpha$ interactions, along with the known association between liprin- $\alpha$ and RIM (Wang et al., 1999) and RIM and a novel active zone protein CAST (Ohtsuka et al., 2002), may play an important role in the organization of active zones.

\section{The GIT1-liprin- $\alpha$ interaction and AMPA receptor targeting}

In this study, we show that disruption of the GIT1-liprin- $\alpha$ interaction with two complementary dominant-negative constructs yields identical results: a marked reduction in dendritic clustering and surface clustering of AMPA receptors. The loss of dendritic clustering was specific for AMPA receptors, whereas NMDA receptors, Shank, and $\alpha$-actinin were unaffected. In addition, the dominant-negatives specifically disrupted the GIT1liprin- $\alpha$ interaction, but not that of KIF1A-liprin- $\alpha$. These results strongly suggest that the GIT1-liprin- $\alpha$ interaction is required for AMPA receptor targeting.

What are the mechanisms underlying the results of our dominant-negative experiments? Interfering with the interaction between GluR2 and GRIP by expression of a dominant-negative construct containing the C-terminal region of GluR2 in cultured neurons dramatically reduces the number of GluR2 synaptic clusters (Dong et al., 1997). GluR2 mutants with defective binding to GRIP exhibit normal targeting to the synaptic surface but show enhanced internalization and limited time-dependent surface accumulation, suggesting that GRIP contributes to the stabilization of AMPA receptors at the synaptic surface (Osten et al., 2000). Interfering with the interaction between GRIP and liprin- $\alpha$ with dominant-negatives disrupts dendritic and surface clustering of AMPA receptors (Wyszynski et al., 2002). Our data indicate that the liprin- $\alpha-$ GIT1 interaction is required for dendritic and surface clustering of AMPA receptors. Thus, we hypothesize that in the context of the AMPA receptor-GRIP-liprin- $\alpha-$ GIT1 interaction, the GIT1-liprin- $\alpha$ interaction may facilitate the physical retention of AMPA receptors at the surface membrane. This possibility is further supported by the fact that GIT1 is substantially enriched in PSD fractions (Fig. 2E), along with GIT1-associated liprin- $\alpha$ (Fig. $2 E$ ) and GRIP (Srivastava et al., 1998; Wyszynski et al., 1998; Dong et al., 1999). Alternatively, GIT1 may actively inhibit the endocytosis of GluR2. It has been shown that GIT1 inhibits the ligand-induced endocytosis of the $\beta 2$-adrenergic receptor in an ARF GAP activity-dependent manner (Premont et al., 1998), whereas ARNO, an ARF GEF, enhances receptor endocytosis (Claing et al., 2001). Furthermore, GIT1 inhibits the ligand-induced endocytosis of various membrane proteins that are internalized through the clathrin-coated pit pathway in a $\beta$-arrestin- and dynamin-sensitive manner (Claing et al., 2000). Because ligand-induced internalization of AMPA receptors also occurs through the clathrin-coated pit pathway in a dynamin-dependent manner (Carroll et al., 1999; Luscher et al., 1999; Lin et al., 2000; Man et al., 2000; Wang and Linden, 2000), it is possible that the endocytosis of ligandinduced AMPA receptors is inhibited by GIT1. The specific action of GIT1 on AMPA, but not NMDA, receptors may be achieved by the recruitment of GIT1 to the close vicinity of AMPA receptors through GRIP and liprin- $\alpha$. Thus our dominant-negatives disrupting the GRIP-liprin- $\alpha$ interaction may lift the inhibitory effects of GIT1 on the endocytosis of AMPA receptors and shift the balance between ARF GAPs and ARF GEFs toward enhanced endocytosis of AMPA receptors. These two possibilities, physical retention and inhibition of endocytosis, may not be mutually exclusive.

Alternatively, the dominant-negative results may arise from defective insertion of AMPA receptors into the surface membrane. Possible sources of AMPA receptor-containing vesicles for insertion are recycling endosomes (Ehlers, 2000; Lin et al., 2000) and the Golgi complex (Broutman and Baudry, 2001; Passafaro et al., 2001). Brefeldin A is a fungal metabolite that affects membrane transport and the structure of the Golgi complex through the inhibition of a Golgi-associated GEF activity for ARFs (Klausner et al., 1992; Chardin and McCormick, 1999; Donaldson and Jackson, 2000). Importantly, brefeldin A inhibits the NMDAinduced translocation of AMPA receptors to synaptic membrane fractions in slices (Broutman and Baudry, 2001) and both constitutive and glycine-induced exocytosis of AMPA receptors in cultured neurons (Passafaro et al., 2001), suggesting that ARFs may regulate the anterograde trafficking of AMPA receptorcontaining vesicles. Among the three known classes of ARF (class I, ARFs 1-3; class II, ARFs 4 and 5; class III, ARF6) (Chavrier and Goud, 1999), ARF1, the best studied isoform, is localized to the Golgi complex and drives the budding of vesicles by recruiting coatomers (COPI, COPII, and clathrin) (Rothman, 1996; Schekman and Orci, 1996; Donaldson and Lippincott-Schwartz, 2000). ARF6 is uniquely localized to the plasma membrane and recycling endosomes and is implicated in the regulation of endosome recycling and remodeling of the actin cytoskeleton (D'SouzaSchorey et al., 1995, 1997; Radhakrishna and Donaldson, 1997). Consistent with their ubiquitous tissue expression, ARF1/3 and ARF6 were shown to be expressed in both embryonic and adult brains and to be involved in the regulation of dendritic branching in cultured neurons (Hernandez-Deviez et al., 2002). However, the involvement of GIT1, which is active for both ARF1 and ARF6 (Premont et al., 1998; Vitale et al., 2000), in the regulation of receptor exocytosis is relatively unknown in comparison with its reported functional association with receptor endocytosis, focal adhesion assembly, and actin cytoskeleton remodeling (Premont et al., 1998; Bagrodia et al., 1999; Turner et al., 1999; Di Cesare et al., 2000; Zhao et al., 2000). However, because ARF GAPs are generally known to coordinate the formation and fusion of vesicles through GTP hydrolysis and recycling of GDP-bound ARFs 
(Chavrier and Goud, 1999; Roth, 1999; Donaldson and Jackson, 2000), it is conceivable that GIT1 may similarly facilitate the exocytosis of AMPA receptors. The intimate association of GIT1 with AMPA receptors would be ensured by liprin- $\alpha$ and GRIP. If this is the case, the dominant-negatives may suppress the GIT1mediated facilitation of the anterograde trafficking of AMPA receptor-containing vesicles, leading to reduced surface expression of AMPA receptors. This hypothesis is consistent with the previous results that GluR2 mutants with defective binding to PDZ-containing proteins are not delivered to synapses (Shi et al., 2001) and show a reduced rate of exocytosis (Passafaro et al., 2001).

To better understand the molecular mechanisms underlying the dominant-negative results, future research will need to address the following questions in detail. Do ARFs (class I and III) regulate AMPA receptor trafficking (endo/exocytosis and regulated/constitutive) at distinct subcellular sites such as recycling endosomes and the Golgi complex? If so, how does GIT1, in concert with ARFs and ARNO, coordinate the trafficking of AMPA receptor-containing vesicles?

In conclusion, this study demonstrates that the interaction between GIT1 and liprin- $\alpha$ is required for AMPA receptor targeting. In addition, GIT1, a multifunctional protein with an ARF GAP activity and various domains for protein interactions, may play an import role in the organization of presynaptic and postsynaptic complexes.

\section{References}

Bagrodia S, Bailey D, Lenard Z, Hart M, Guan JL, Premont RT, Taylor SJ, Cerione RA (1999) A tyrosine-phosphorylated protein that binds to an important regulatory region on the cool family of p21-activated kinasebinding proteins. J Biol Chem 274:22393-22400.

Broutman G, Baudry M (2001) Involvement of the secretory pathway for AMPA receptors in NMDA-induced potentiation in hippocampus. J Neurosci 21:27-34.

Bruckner K, Pablo Labrador J, Scheiffele P, Herb A, Seeburg PH, Klein R (1999) EphrinB ligands recruit GRIP family PDZ adaptor proteins into raft membrane microdomains. Neuron 22:511-524.

Carroll RC, Beattie EC, Xia H, Luscher C, Altschuler Y, Nicoll RA, Malenka RC, von Zastrow M (1999) Dynamin-dependent endocytosis of ionotropic glutamate receptors. Proc Natl Acad Sci USA 96:14112-14117.

Chardin P, McCormick F (1999) Brefeldin A: the advantage of being uncompetitive. Cell 97:153-155.

Chavrier P, Goud B (1999) The role of ARF and Rab GTPases in membrane transport. Curr Opin Cell Biol 11:466-475.

Claing A, Perry SJ, Achiriloaie M, Walker JK, Albanesi JP, Lefkowitz RJ, Premont RT (2000) Multiple endocytic pathways of G protein-coupled receptors delineated by GIT1 sensitivity. Proc Natl Acad Sci USA 97:1119-1124.

Claing A, Chen W, Miller WE, Vitale N, Moss J, Premont RT, Lefkowitz RJ (2001) beta-Arrestin-mediated ADP-ribosylation factor 6 activation and beta 2-adrenergic receptor endocytosis. J Biol Chem 276:42509-42513.

Di Cesare A, Paris S, Albertinazzi C, Dariozzi S, Andersen J, Mann M, Longhi $\mathrm{R}$, de Curtis I (2000) p95-APP1 links membrane transport to Racmediated reorganization of actin. Nat Cell Biol 2:521-530.

Donaldson JG, Jackson CL (2000) Regulators and effectors of the ARF GTPases. Curr Opin Cell Biol 12:475-482.

Donaldson JG, Lippincott-Schwartz J (2000) Sorting and signaling at the Golgi complex. Cell 101:693-696.

Dong H, O’Brien RJ, Fung ET, Lanahan AA, Worley PF, Huganir RL (1997) GRIP: a synaptic PDZ domain-containing protein that interacts with AMPA receptors. Nature 386:279-284.

Dong H, Zhang P, Song I, Petralia RS, Liao D, Huganir RL (1999) Characterization of the glutamate receptor-interacting proteins GRIP1 and GRIP2. J Neurosci 19:6930-6941.

D’Souza-Schorey C, Li G, Colombo MI, Stahl PD (1995) A regulatory role for ARF6 in receptor-mediated endocytosis. Science 267:1175-1178.

D'Souza-Schorey C, Boshans RL, McDonough M, Stahl PD, Van Aelst L
(1997) A role for POR1, a Rac1-interacting protein, in ARF6-mediated cytoskeletal rearrangements. EMBO J 16:5445-5454.

Ehlers MD (2000) Reinsertion or degradation of AMPA receptors determined by activity-dependent endocytic sorting. Neuron 28:511-525.

Fenster SD, Chung WJ, Zhai R, Cases-Langhoff C, Voss B, Garner AM, Kaempf U, Kindler S, Gundelfinger ED, Garner CC (2000) Piccolo, a presynaptic zinc finger protein structurally related to bassoon. Neuron 25:203-214.

Girault JA, Costa A, Derkinderen P, Studler JM, Toutant M (1999) FAK and PYK2/CAKbeta in the nervous system: a link between neuronal activity, plasticity and survival? Trends Neurosci 22:257-263.

Hernandez-Deviez DJ, Casanova JE, Wilson JM (2002) Regulation of dendritic development by the ARF exchange factor ARNO. Nat Neurosci 5:623-624.

Huang Y, Lu W, Ali DW, Pelkey KA, Pitcher GM, Lu YM, Aoto H, Roder JC, Sasaki T, Salter MW, MacDonald JF (2001) CAKbeta/Pyk2 kinase is a signaling link for induction of long-term potentiation in CA1 hippocampus. Neuron 29:485-496.

Kaufmann N, DeProto J, Ranjan R, Wan H, Van Vactor D (2002) Drosophila liprin-a and the receptor phosphatase Dlar control synapse morphogenesis. Neuron 34:27-38.

Kim E, Niethammer M, Rothschild A, Jan YN, Sheng M (1995) Clustering of Shaker-type K+ channels by interaction with a family of membraneassociated guanylate kinases. Nature 378:85-88.

Kim S, Ko J, Shin H, Lee JR, Lim C, Han JH, Altrock WD, Garner CC, Gundelfinger ED, Premont RT, Kaang BK, Kim E (2003) The GIT family of proteins forms multimers and associates with the presynaptic cytomatrix protein Piccolo. J Biol Chem, in press.

Klausner RD, Donaldson JG, Lippincott-Schwartz J (1992) Brefeldin A: insights into the control of membrane traffic and organelle structure. J Cell Biol 116:1071-1080.

Lin D, Gish GD, Songyang Z, Pawson T (1999) The carboxyl terminus of B class ephrins constitutes a PDZ domain binding motif. J Biol Chem 274:3726-3733.

Lin JW, Ju W, Foster K, Lee SH, Ahmadian G, Wyszynski M, Wang YT, Sheng M (2000) Distinct molecular mechanisms and divergent endocytotic pathways of AMPA receptor internalization. Nat Neurosci 3:1282-1290.

Luscher C, Xia H, Beattie EC, Carroll RC, von Zastrow M, Malenka RC, Nicoll RA (1999) Role of AMPA receptor cycling in synaptic transmission and plasticity. Neuron 24:649-658.

Man YH, Lin JW, Ju WH, Ahmadian G, Liu L, Becker LE, Sheng M, Wang YT (2000) Regulation of AMPA receptor-mediated synaptic transmission by clathrin-dependent receptor internalization. Neuron 25:649-662.

Manabe R, Kovalenko M, Webb DJ, Horwitz AR (2002) GIT1 functions in a motile, multi-molecular signaling complex that regulates protrusive activity and cell migration. J Cell Sci 115:1497-1510.

Ohtsuka T, Takao-Rikitsu E, Inoue E, Inoue M, Takeuchi M, Matsubara K, Deguchi-Tawarada M, Satoh K, Morimoto K, Nakanishi H, Takai Y (2002) Cast: a novel protein of the cytomatrix at the active zone of synapses that forms a ternary complex with RIM1 and munc13-1. J Cell Biol 158:577-590.

Osten P, Khatri L, Perez JL, Kohr G, Giese G, Daly C, Schulz TW, Wensky A, Lee LM, Ziff EB (2000) Mutagenesis reveals a role for ABP/GRIP binding to GluR2 in synaptic surface accumulation of the AMPA receptor. Neuron 27:313-325.

Parnas D, Haghighi AP, Fetter RD, Kim SW, Goodman CS (2001) Regulation of postsynaptic structure and protein localization by the Rho-type guanine nucleotide exchange factor dPix. Neuron 32:415-424.

Passafaro M, Piech V, Sheng M (2001) Subunit-specific temporal and spatial patterns of AMPA receptor exocytosis in hippocampal neurons. Nat Neurosci 4:917-926.

Premont RT, Claing A, Vitale N, Freeman JL, Pitcher JA, Patton WA, Moss J, Vaughan M, Lefkowitz RJ (1998) beta2-Adrenergic receptor regulation by GIT1, a G protein-coupled receptor kinase-associated ADP ribosylation factor GTPase-activating protein. Proc Natl Acad Sci USA 95:14082-14087.

Premont RT, Claing A, Vitale N, Perry SJ, Lefkowitz RJ (2000) The GIT family of ADP-ribosylation factor GTPase-activating proteins. Functional diversity of GIT2 through alternative splicing. J Biol Chem 275:22373-22380.

Radhakrishna H, Donaldson JG (1997) ADP-ribosylation factor 6 regulates a novel plasma membrane recycling pathway. J Cell Biol 139:49-61. 
Roth MG (1999) Snapshots of ARF1: implications for mechanisms of activation and inactivation. Cell 97:149-152.

Rothman JE (1996) The protein machinery of vesicle budding and fusion. Protein Sci 5:185-194.

Schekman R, Orci L (1996) Coat proteins and vesicle budding. Science 271:1526-1533.

Schoch S, Castillo PE, Jo T, Mukherjee K, Geppert M, Wang Y, Schmitz F, Malenka RC, Sudhof TC (2002) RIM1 forms a protein scaffold for regulating neurotransmitter release at the active zone. Nature 415:321-326.

Serra-Pages C, Kedersha NL, Fazikas L, Medley Q, Debant A, Streuli M (1995) The LAR transmembrane protein tyrosine phosphatase and a coiled-coil LAR-interacting protein co-localize at focal adhesions. EMBO J 14:2827-2838.

Shi S, Hayashi Y, Esteban JA, Malinow R (2001) Subunit-specific rules governing AMPA receptor trafficking to synapses in hippocampal pyramidal neurons. Cell 105:331-343.

Srivastava S, Osten P, Vilim FS, Khatri L, Inman G, States B, Daly C, DeSouza S, Abagyan R, Valtschanoff JG, Weinberg RJ, Ziff EB (1998) Novel anchorage of GluR2/3 to the postsynaptic density by the AMPA receptorbinding protein ABP. Neuron 21:581-591.

Torres R, Firestein BL, Dong H, Staudinger J, Olson EN, Huganir RL, Bredt DS, Gale NW, Yancopoulos GD (1998) PDZ proteins bind, cluster, and synaptically colocalize with Eph receptors and their ephrin ligands. Neuron 21:1453-1463.

Turner CE (2000) Paxillin interactions. J Cell Sci 113:4139-4140.

Turner CE, Brown MC, Perrotta JA, Riedy MC, Nikolopoulos SN, McDonald AR, Bagrodia S, Thomas S, Leventhal PS (1999) Paxillin LD4 motif binds PAK and PIX through a novel $95-\mathrm{kD}$ ankyrin repeat, ARF-GAP protein: a role in cytoskeletal remodeling. J Cell Biol 145:851-863.

Vitale N, Patton WA, Moss J, Vaughan M, Lefkowitz RJ, Premont RT (2000) GIT proteins, a novel family of phosphatidylinositol 3,4,5-trisphosphate- stimulated GTPase-activating proteins for ARF6. J Biol Chem 275: 13901-13906.

Wang X, Kibschull M, Laue MM, Lichte B, Petrasch-Parwez E, Kilimann MW (1999) Aczonin, a 550-kD putative scaffolding protein of presynaptic active zones, shares homology regions with Rim and Bassoon and binds profilin. J Cell Biol 147:151-162.

Wang YT, Linden DJ (2000) Expression of cerebellar long-term depression requires postsynaptic clathrin-mediated endocytosis. Neuron 25:635-647.

Wenthold RJ, Petralia RS, Blahos J, II, Niedzielski AS (1996) Evidence for multiple AMPA receptor complexes in hippocampal CA1/CA2 neurons. J Neurosci 16:1982-1989.

Wyszynski M, Kim E, Yang FC, Sheng M (1998) Biochemical and immunocytochemical characterization of GRIP, a putative AMPA receptor anchoring protein, in rat brain. Neuropharmacology 37:1335-1344.

Wyszynski M, Valtschanoff JG, Naisbitt S, Dunah AW, Kim E, Standaert DG Weinberg R, Sheng M (1999) Association of AMPA receptors with a subset of glutamate receptor-interacting protein in vivo. J Neurosci 19:6528-6537.

Wyszynski M, Kim E, Dunah AW, Passafaro M, Valtschanoff JG, Serra-Pages C, Streuli M, Weinberg RJ, Sheng M (2002) Interaction Between GRIP and liprin-a/SYD2 required for AMPA receptor targeting. Neuron 34:39-52.

Ye B, Liao D, Zhang X, Zhang P, Dong H, Huganir RL (2000) GRASP-1: a neuronal RasGEF associated with the AMPA receptor/GRIP complex. Neuron 26:603-617.

Zhao ZS, Manser E, Loo TH, Lim L (2000) Coupling of PAK-interacting exchange factor PIX to GIT1 promotes focal complex disassembly. Mol Cell Biol 20:6354-6363.

Zhen M, Jin Y (1999) The liprin protein SYD-2 regulates the differentiation of presynaptic termini in C. elegans. Nature 401:371-375. 